\title{
Applying Health in All Policies at the University of Wisconsin-Madison
}

\author{
$\underline{\text { Amina Maamouri }}^{1}$, Nova Tebbe $^{2}, \underline{\text { Chris Unterberger }}^{3}$ \\ ${ }^{1}$ University of Wisconsin-Madison, School of Medicine and Public Health, MD/MPH Program, Madison, WI \\ ${ }^{2}$ University of Wisconsin-Madison, School of Medicine and Public Health and La Follette School of Public \\ Affairs, MPH-MPA Dual Degree Program, Madison, WI \\ ${ }^{3}$ University of Wisconsin-Madison, School of Pharmacy, Pharmaceutical Sciences Division, Madison, WI \\ https://doi.org/10.38126/JSPG190107
}

Corresponding author: cjunterberger@gmail.com

Keywords: health in all policies; COVID-19; health impact assessment; public health; university governance; health equity; collaboration

\begin{abstract}
Executive Summary: The University of Wisconsin-Madison's (UW-Madison) response to the COVID-19 pandemic demonstrates how prioritizing health in campus policies is necessary to achieve better health, educational, and workforce outcomes. COVID-19 cases increased on campus as students attended in-person classes at the beginning of the 2020-21 academic year, though dampened as the university ramped up protective measures. Harm may have been prevented had proactive and analytical approaches to policy making, which are foundational to a Health in All Policies (HiAP) approach, been implemented sooner. Specifically, comprehensive and rapid Health Impact Assessments could enhance university leadership's ability to mitigate the negative effects of existing and future policies. Here, we recognize the COVID-19 pandemic as a justifiable catalyst for implementing a HiAP approach in UW-Madison policymaking. We recommend that the university establish a HiAP subcommittee within the Division of Diversity, Equity \& Educational Achievement. This action standardizes the use of tools essential to HiAP across campus while limiting the demand on existing university committees and other administrative offices.
\end{abstract}

\section{The University of Wisconsin-Madison's} Response to the COVID-19 Pandemic

When the COVID-19 pandemic was in its early stages in March 2020, little was known about how the virus transmitted or its prevention. However, one thing was clear: the health and wellbeing of people should be the top priority. Many of the policies and actions taken by local, state, and federal governments, such as mask mandates, lockdowns, and physical distancing, tried to prevent mortality. As the COVID-19 pandemic worsened over the coming months, pillars of society began to suffer. People started losing jobs, education was disrupted as students transitioned to online formats, disparities in housing began to deepen (Pew Research 2020), and deep-rooted systemic racism became more apparent (CDC 2020). The pandemic has shown how health and wellbeing are interconnected in all aspects of society.

The University of Wisconsin-Madison (UW-Madison) has seen what happens when health is not the foundation of campus policies. The "Smart Restart" plan for Fall 2020 included on-campus drop-in testing, in-person classes with no more than 50 students, mask mandates, and operation of all its residence halls with enhanced safety protocols for shared spaces (University of Wisconsin-Madison, June 2020). Despite these plans for the Fall 2020 semester, the seven-day average positive rate increased from $2.0 \%$ on September 2 nd to $10.2 \%$ on September 13th (University of Wisconsin-Madison, 2020). By September 9th, the Chancellor instituted two weeks of remote instruction and quarantined two residence halls, disrupting education and 
student jobs (University of Wisconsin-Madison, September 2020). The health of students, staff, and faculty were threatened, and as a result, university functions were stalled.

In early January 2021, the university increased testing and introduced the SaferBadgers app for students, staff, and faculty with information about COVID-19 resources and up-to-date testing results. As a result, positive cases were identified more quickly and rates declined (University of Wisconsin-Madison 2021). The introduction of vaccines also helped to decline rates on campus and in the surrounding Madison area, with 36,528 students and faculty at least partially vaccinated by May 9th (University of Wisconsin-Madison 2021). In Spring 2021, health was prioritized and central in campus policies which allowed the University to resume operations through a hybrid model of in-person and online learning, and support education, employment, and wellbeing within the campus community.

The ongoing COVID-19 pandemic has shown the importance of implementing policies that are founded in health. Unfortunately, a pandemic, or rather a large increase in COVID-19 cases directly affecting students, faculty, and staff, was required to prioritize health in every policy on campus. However, there is a unique opportunity to continue to address the many connections between health and society on campus and in the community, by implementing a Health in All Policies (HiAP) approach.

\section{Health in All Policies}

HiAP is a collaborative approach to improving the health of all people by incorporating health and equity considerations into decision-making across sectors (Rudolph et al. 2013). This approach includes five key elements: 1 ) promoting health and equity, 2) supporting intersectoral collaboration, 3) creating co-benefits for multiple partners, 4) engaging stakeholders, and 5) creating structural or process change. As such, HiAP does not refer to a specific set of policies but rather to an array of strategies for integrating health into policymaking (Hall and Jacobson 2018). This flexibility is key to its broad, positive impacts because every community has its own beliefs on what constitutes health and the policies needed to realize that goal.

Health Impact Assessments (HIAs) are HiAP tools that serve as systematic assessments of the health effects of a policy, practice, or program on specific populations to maximize beneficial effects and minimize adverse ones (Gottlieb, Egerter, \& Braveman 2011). Comprehensive HIAs typically take up to six months and involve an extensive literature search, in-depth interviews and surveys, and collaboration among multiple stakeholders. Alternatively, rapid HIAs are less intensive tools that often utilize a standardized checklist of criteria for decision-makers to consider. HIAs are conducted collaboratively, but often guided by public health practitioners or government leaders who are trained to facilitate the process. These assessments can be conducted prospectively to guide decision-making or retrospectively to assess pre-existing policies and identify areas for improvement. When used prospectively, HIAs have shown to be successful in 1) incorporating health perspectives into decision-making processes, 2) increasing awareness of health impacts among decision-makers, and 3) positively influencing decisions. HiAP not only helps decision-makers be informed of how decisions across sectors affect health, but how health can support various sectors in achieving their goals. To effectively move health science knowledge into action, this dual understanding among decision-makers is valuable to garnering support and positive outcomes.

HiAP has been gaining acceptance across the U.S. over the past decade, including among local governments, state agencies, academic partners, and nonprofit groups in Wisconsin. These entities, as part of the Legacy Community Alliance for Health (LCAH), received one million dollars from the Wisconsin Partnership Program to improve health and health equity across Wisconsin by integrating HiAP into local policy-making (Legacy Community Alliance for Health Overview 2018). LCAH has been successful in formally and informally integrating HiAP into local governance. The City of Appleton became the first city in Wisconsin to formally pass a HiAP ordinance in December 2017 which requires the City to 1) utilize health equity practices, an HiAP 
strategy document, and a community engagement plan, and 2) establish an Interdepartmental HiAP Team of department representatives to set and track indicators, attend relevant trainings, and conduct a tri-annual report on the progress of HiAP implementation and evolving status of health and health equity (Common Council of the City of Appleton 2017). Interest in HiAP has also grown on a state level in Wisconsin. In February 2021, Governor Evers proposed creating a HiAP Action Team which would "organize representatives from all executive branch agencies to create a shared vision of healthy and equitable communities, define common goals, explore the root causes of health, create a collective action plan, implement HiAP within their agencies, and engage their stakeholders in conversations about what creates health" (Evers 2021). Though the budget process has not been completed yet, the proposal reflects elevated state-wide interest in HiAP, especially during COVID-19 recovery.

UW-Madison operates like a mini-city in that it is made up of governance structures, health services, food systems, housing, and transportation infrastructure. Interestingly, there are no universities that explicitly utilize a HiAP approach. Given the contextual similarities to municipalities, universities, like UW-Madison, should apply existing HiAP strategies to experience many of the same benefits of other large organizations.

\section{Policy Options}

i. Option 1: Coordinate within vice chancellors' offices to conduct annual, comprehensive HIAs and require the use of rapid HIAs within vice chancellors' offices and university committees

UW-Madison's organizational structure delegates a large portion of its decision-making to vice chancellors' offices across campus. The eight vice chancellors that report to the chancellor oversee numerous associate vice chancellors, deans, directors, and other administrators. This complex governance structure necessitates standardization of assessment for the policies implemented across the university. Comprehensive HIAs mandated within each vice chancellor's office, and overseen by the Chancellor's Office, will ensure adequate information is available regarding the health and equity impacts of existing university policies. Likewise, prospective rapid HIAs conducted during policy formation and prior to implementation will allow vice chancellors' offices to anticipate and address the health and equity effects of policies across their authority. Mobilizing Action Toward Community Health (MATCH) is an existing program in the Population Health Institute at UW-Madison with HiAP expertise to train vice chancellors' offices to conduct HIAs. The process of conducting these assessments will engage multiple stakeholders (e.g., students, staff, faculty, administration) which increases the visibility of assessment findings and encourages accountability to act on findings.

\section{Advantages:}

- Standardizes assessments across campus

- Provides both retrospective analysis and proactive anticipation with the inclusion of comprehensive HIAs and rapid HIAs, respectively

- Assesses the health and equity impact of seemingly unrelated university policies within each vice chancellor's domain

- Fosters engagement of stakeholders across campus, such as students, staff, and faculty, among others

\section{Disadvantages:}

- Upfront costs of implementation and training within each office

- Varying acceptance between offices is expected

- By themselves, assessment findings do not ensure that health and equity are reflected in new university policies

ii. Option 2: Establish a university-wide committee to ensure HiAP compliance in decision-making across campus. Delegate HiAP training and oversight to a new UW-Madison committee within the Division of Diversity, Equity \& Educational Achievement (DDEEA) No university-wide offices or committees currently exist that are capable of the oversight and training necessary to sufficiently implement HiAP across campus. However, the DDEEA has the infrastructure in place to implement HiAP at UW-Madison in the future. The DDEEA has a dedicated Chief Diversity Officer who provides leadership for the university's 
efforts to create a diverse, equitable and inclusive learning and working environment and helps create policies and resources that promote diversity, equity, and inclusion across campus. A HiAP committee housed within the DDEEA will be able to most easily apply the assessment and educational resources at the division's disposal to ensure HiAP compliance across campus with enforcement support from the Chancellor's Office. HiAP experts from MATCH could utilize a "train the trainer" model to build capacity within the new DDEEA committee to train other offices and committees across UW-Madison to implement HiAP.

\section{Advantages:}

- Ensures the process of conducting HIAs is equitable and inclusive and that HIA findings are incorporated into decision making across various offices and committees on campus

- Provides an external office for all other UW-Madison offices and committees to access to implement HiAP and comply with HiAP requirements

- Builds partnerships across the university's decision-makers

\section{Disadvantages:}

- Slows the policymaking process of other committees and offices on campus by necessitating the inclusion of an outside committee for review

- Diverts limited resources within DDEEA to HiAP compliance and training

- MATCH training does not ensure DDEEA personnel will develop the expertise to properly train other offices and committees to implement HiAP.

iii. Option 3: Take no action in implementing HiAP at UW-Madison

UW-Madison has functioned since 1848 without HiAP strategies in its policymaking. The university would be the first educational institution to enforce such a framework across its organizational structure.

Advantages:

- Avoids logistical issues of implementation and compliance of HiAP
- Maintains autonomy amongst university committees and offices

\section{Disadvantages:}

- Does not address failures in policymaking that became apparent following the COVID-19 pandemic

- Leaves space for disparate policy implementation across the university organizational structure

- Does not ensure health and equity are considered in university policies

- Fails to implement a much-needed policy compliance system that involves a variety of stakeholders

\section{iv. Policy considerations}

UW-Madison's vast organizational structure provides a sense of shared governance across campus but creates variability in policies. Policies that are implemented must be done so with consideration not to infringe on offices' independence. This concern is largely subsided by acknowledging that HiAP is simply a collaborative approach to the decision-making process and HIAs are only an assessment tool; so, any policy changes within offices or committees will be made wholly independent. Importantly, contributions to the reporting requirements or a newly formed committee must include voices of all stakeholders on campus including students, staff, faculty, and administrators. These efforts must also highlight perspectives from the underrepresented groups that are most drastically impacted by university policies including people of color, those belonging to the LGBTQ+ community, and low-income community members. Lastly, assessment findings should be shared publicly to foster transparency in the decision-making process and accountability to act in the interests of health and equity.

\section{Policy Recommendation}

We recommend Option 2, which establishes a university-wide committee to ensure HiAP compliance in decision-making across campus by creating a new UW-Madison committee within the DDEEA to oversee and train other committees and offices in HiAP-based policymaking. This option provides the most impact across campus by 
standardizing the use of tools essential to HiAP, while limiting the demand on existing university committees and offices.

With a HiAP committee in place, UW-Madison will be better able to respond to difficult situations like the COVID-19 pandemic in the future. Implementing HiAP at the university level is innovative and provides UW-Madison leadership the opportunity to

\section{References}

CDC. 2020. "Community, Work, and School." Centers for Disease Control and Prevention. February 11, 2020.

https://www.appleton.org/home/showpublished document/22076/636830684765200000.

Common Council of the City of Appleton, Timothy Hanna, and Kami Lynch. 2017. An Ordinance Creating Article $V$ of Chapter 7 of the Municipal Code of the City of Appleton, Relating to Health in All Policies. https://www.appleton.org/home/showpublished document/22076/636830684765200000.

Gottlieb, Laura, Susan Egerter, and Paula Braveman. 2011. Health Impact Assessment: A Tool for Promoting Health in All Policies. Robert Wood Johnson Foundation. (May 1, 2011).

Evers, Tony. 2021. "State of Wisconsin Budget in Brief." 2021-2023 Executive Budget. Wisconsin Department of Administration, February 2021. https://doa.wi.gov/budget/SBO/2021-23\%20Bu dget $\% 20$ in $\% 20$ Brief.pdf.

Hall, Richard L., and Peter D. Jacobson. 2018. "Examining Whether the Health-In-All-Policies Approach Promotes Health Equity." Health Affairs 37, no. 3: 364-70.

https://doi.org/10.1377/hlthaff.2017.1292.

"Legacy Community Alliance for Health Overview." Madison: UW Population Health Institute, March 2018. pioneer this approach and to serve as a model for how to most equitably approach university-wide policymaking.
Pew Research. 2020. "Most Americans Say Coronavirus Outbreak Has Impacted Their Lives." March 2020. https://www.pewresearch.org/social-trends/202 0/03/30/most-americans-say-coronavirus-outbr eak-has-impacted-their-lives/

Rudolph, L., Caplan, J., Ben-Moshe, K., \& Dillon, L. 2013. Health in All Policies: A Guide for State and Local Governments. Washington, DC and Oakland, CA: American Public Health Association and Public Health Institute.

University of Wisconsin-Madison. n.d. "Dashboard 2020." COVID-19 Response. Accessed May 24, 2021. https://covidresponse.wisc.edu/dashboard-2020 L.

University of Wisconsin-Madison. n.d. "Dashboard, Jan. 1-May 9, 2021." COVID-19 Response. Accessed May 24, 2021. https://covidresponse.wisc.edu/dashboard/

University of Wisconsin-Madison. 2020. "University Announces Smart Restart Plan to

Reopen in Fall." University of Wisconsin-Madison News. June 17, 2020.

https://news.wisc.edu/university-announces-sm art-restart-plan-to-reopen-in-fall/

University of Wisconsin-Madison. 2020. "University Shifts to Two Weeks of Remote

Instruction, Quarantines Two Residence Halls." September 9, 2020.

https://news.wisc.edu/university-shifts-to-twoweeks-remote-instruction/

Amina Maamouri (she/her) is a Medical and Master of Public Health student at the University of Wisconsin-Madison. She is passionate about advancing health equity in Wisconsin using social change strategies such as multi-sector coalitions, community organizing, and advocacy. Amina is a founding member of Wisconsin Advocates for Public Health where she encourages student and professional engagement, supports knowledge and skill development, and collaborates in advocating for public health and equity. In her future clinical practice, she aims to improve individual health while working with patients to build community power and address upstream social, political, and commercial determinants of health.

Nova Tebbe (she/her) is a dual-degree Master of Public Health and Master of Public Affairs and an Energy Analysis and Policy Certificate student at the University of Wisconsin-Madison. She works as a policy analyst for Dr. Jonathan Patz focusing on climate change, health, and equity on the state, national, and international 
levels. Nova is a member of Wisconsin Advocates for Public Health where she designs communication deliverables and advocates for environmental justice on a system-level.

Chris Unterberger is a PhD candidate in the Pharmaceutical Sciences Division at the University of Wisconsin-Madison where his research focuses on investigating the role of growth hormone in prostate and mammary cancer. He is the co-president of UW-Madison's Catalysts for Science Policy (CaSP) and chairs the Grants \& Finance Committee of the National Science Policy Network. He writes science-focused articles for the Adams-Friendship Times-Reporter in his hometown in Wisconsin and contributes to policy memos written for state legislators through CaSP's Wisconsin Science \& Technology Advisors initiative. 